\title{
A pri-miR-218 variant and risk of cervical carcinoma in Chinese women
}

\author{
Ting-Yan Shi ${ }^{1,5}$, Xiao-Jun Chen ${ }^{2,5}$, Mei-Ling Zhu ${ }^{1,5}$, Meng-Yun Wang ${ }^{1,5}$, Jing He ${ }^{1,5}$, Ke-Da Yu ${ }^{3,5}$, Zhi-Ming Shao ${ }^{1,3,5}$, \\ Meng-Hong Sun ${ }^{4,5}$, Xiao-Yan Zhou ${ }^{4,5}, X_{\text {C Cheng }}^{2,5}$, Xiaohua Wu $u^{2,5^{*}}$ and Qingyi Wei ${ }^{1,6^{*}}$
}

\begin{abstract}
Background: MicroRNA (miRNA)-related single nucleotide polymorphisms (SNPs) may compromise miRNA binding affinity and modify mRNA expression levels of the target genes, thus leading to cancer susceptibility. However, few studies have investigated roles of miRNA-related SNPs in the etiology of cervical carcinoma.
\end{abstract}

Methods: In this case-control study of 1,584 cervical cancer cases and 1,394 cancer-free female controls, we investigated associations between two miR-218-related SNPs involved in the LAMB3-miR-218 pathway and the risk of cervical carcinoma in Eastern Chinese women.

Results: We found that the pri-miR-218 rs11134527 variant GG genotype was significantly associated with a decreased risk of cervical carcinoma compared with AA/AG genotypes (adjusted $O R=0.77,95 \% \mathrm{Cl}=0.63-0.95$, $P=0.015$ ). However, this association was not observed for the miR-218 binding site SNP (rs2566) on LAMB3. Using the multifactor dimensionality reduction analysis, we observed some evidence of interactions of these two SNPs with other risk factors, especially age at primiparity and menopausal status, in the risk of cervical carcinoma.

Conclusions: The pri-miR-218 rs11134527 SNP was significantly associated with the risk of cervical carcinoma in Eastern Chinese women. Larger, independent studies are warranted to validate our findings.

Keywords: Case-control study, Cervical cancer, LAMB3-miR-218 pathway, Polymorphism, Genetic susceptibility

\section{Background}

MicroRNAs (miRNAs) are single-stranded 21-23 nucleotide (nt) long endogenous noncoding RNAs that regulate the mRNA expression of numerous target genes [1]. Disregulation of these target genes could alter biological processes as a result of either degradation of target mRNAs or repression of their translation by miRNA binding to their $3^{\prime}$-untranslated regions (UTRs) [2]. Accumulated data have shown that the deregulation of miRNAs is involved in cell differentiation, proliferation, apoptosis and carcinogenesis [3]. MiRNAs include primary (pri-), precursor (pre-) and mature miRNA, in which single nucleotide polymorphisms (SNPs) of these miRNAs or in their binding sites on their target genes may compromise miRNA binding affinity and change mRNA expression levels of the target genes, thus leading

\footnotetext{
* Correspondence: docwuxh@hotmail.com; qwei@mdanderson.org

${ }^{2}$ Department of Gynecologic Oncology, Fudan University Shanghai Cancer Center, Shanghai, China

${ }^{1}$ Cancer Institute, Fudan University Shanghai Cancer Center, Shanghai, China

Full list of author information is available at the end of the article
}

to cancer susceptibility $[4,5]$. Several recent studies have indicated that miRNA-related SNPs, especially those located at miRNA binding sites or miRNAs themselves, can remarkably alter the biogenesis and/or function of the corresponding miRNAs and thus the risk of human cancers $[4,6]$.

Cervical carcinoma is the third most commonly diagnosed cancer and the fourth leading cause of cancer deaths in women worldwide, accounting for $9 \%$ $(529,800)$ of the new cancer cases and $8 \%(275,100)$ of the cancer deaths among women in 2008 [7]. More than $85 \%$ of these cases and deaths occur in developing countries, including China [7]. Invasive cervical cancer can be divided into two major histological types of squamous cell carcinoma (SCC) and adenocarcinoma, and SCC accounts for about $85 \%$ of the cases [8,9]. A large body of research in molecular epidemiology supports the hypothesis that persistent infection with oncogenic human papillomavirus (HPV), especially high-risk HPV types, is

\section{Biomed Central}

(C) 2013 Shi et al.; licensee BioMed Central Ltd. This is an Open Access article distributed under the terms of the Creative Commons Attribution License (http://creativecommons.org/licenses/by/2.0), which permits unrestricted use, distribution, and reproduction in any medium, provided the original work is properly cited. 
the primary cause of cervical carcinoma, deemed as a necessary cause for the disease $[7,10]$.

Recent studies have found that the expression levels of $m i R-218$ were associated with infection of high-risk HPV involved in the pathogenesis of cervical cancer [11]. Specifically, in high-risk HPV16-positive cell lines, the upregulation of E6 oncoprotein could reduce the miR-218 expression; in contrast, the RNA interference of E6 oncogene increased the miR-218 expression [12]. Moreover, the Laminin $5 \beta 3$ (LAMB3) gene has been found to be one of transcriptional targets of miR-218 [12]. $L A M B 3$ was expressed in many epithelial tissues and was involved in tumor microenvironment by increasing carcinoma cell migration [13]. Others reported that $L A M B 3$ might upregulate the expression levels of the HPV16 E6 oncoprotein though miR-218 [12]. Therefore, the LAMB3-miR-218 pathway may be involved in the process of high-risk HPV infection and thus contribute to cervical carcinogenesis. However, its intrinsic mechanisms are still unclear. It is likely that miRNAs and related genetic variations may have effects on cancer development [6]. To date, only two reported studies have investigated the associations between three miRNA-related SNPs and the risk of cervical carcinoma [6,14], two of which (i.e., pri-miR-218 rs11134527 and $L A M B 3$ rs2566) are found to be associated with altered risk of cervical cancer in a Chinese Han population [6]. To further test the hypothesis that miRNA-related SNPs involved in the LAMB3-miR-218 pathway contribute to cervical cancer risk, we performed a case-control study with a much larger sample size to validate the reported associations with cervical cancer risk in Eastern Chinese women.

\section{Methods}

\section{Study subjects}

The study population consisted of 1,584 cervical carcinoma patients, who had been operated between February 2008 and March 2011 in Fudan University Shanghai Cancer Center (FUSCC). The tumors were histopathologically confirmed independently as primary cervical carcinoma by two gynecologic pathologists as routine diagnosis at FUSCC. An additional 1,394 cancer-free female controls were enrolled from women who had come to the Outpatient Department of Breast Surgery at FUSCC for breast cancer screening and agreed to participate in this study. These female controls, with the selection criteria including no individual history of cancer, were genetically unrelated and frequency matched to the cases on age ( \pm 5 years) and residential areas in Eastern China.

During an in-person survey, all potential subjects were interviewed to identify their willingness to participate in this study. As a result, a response rate for the cases and controls was of approximate $95 \%$ and $95 \%$, respectively. Because the vast majority of Chinese women are nonsmokers and non-drinkers, our study populations were restricted to women who did not smoke cigarettes or drink alcohol. For the cases, detailed clinico-pathologic information was extracted from the patients/ electronic database of FUSCC, including tumor histology [15], FIGO stage (International Federation of Gynecology and Obstetrics, 2009), tumor size (i.e., the size of the primary tumor was the largest tumor diameter), pelvic lymph node (LN) metastasis, lympho-vascular space invasion (LVSI), depth of cervical stromal invasion and the expression of estrogen receptor (ER) and progesterone receptor (PR). Each participant provided a one-time $10 \mathrm{ml}$ of venous blood sample (after the diagnosis and before the initiation of treatment for the cases), and samples were kept frozen till DNA extraction for genotyping. All samples were obtained from tissue bank of FUSCC. The research was approved by the Institutional Review Board of FUSCC, and a written informed consent was obtained from all recruited individuals. Each clinical investigation was conducted according to the principles expressed in the Declaration of Helsinki consent.

\section{SNP selection and genotyping}

The SNPs were selected from the NCBI dbSNP database (http://www.ncbi.nlm.nih.gov/projects/SNP) and the International HapMap Project database (http://hapmap. ncbi.nlm.nih.gov/) based on four criteria: 1) located at the pri-miR-218 gene region or 3'-UTR of the LAMB3 gene, 2) minor allele frequency (MAF) $\geq 5 \%$ in Chinese Han populations, 3) with low linkage disequilibrium by using an $r^{2}$ threshold of $<0.8$ for each other, and 4) predicted as potentially functional SNPs by SNP function prediction (FuncPred) software from National Institute of Environmental Health Sciences (http://snpinfo.niehs.nih. gov/snpfunc.htm). As a result, only two reported SNPs (i.e., pri-miR-218 rs11134527 and LAMB3 rs2566) were selected, because pri-miR-218 rs11134527 was predicted to be functional and $L A M B 3$ rs2566 was the only one SNP residing in the miR-218 binding site. Genomic DNA was obtained from the whole blood, and the Taqman assay was performed for genotyping, as described previously $[16,17]$. Four negative controls (without DNA template), duplicated positive controls and eight repeat samples were included in each 384-fomate for the quality control. As a result, the mean genotyping rate was $99.3 \%$, and the discrepancy rate in all positive controls (i.e., duplicated samples, overlapping samples from previous studies and samples randomly selected to be sequenced) was less than $0.1 \%$.

\section{Multifactor dimensionality reduction (MDR) analysis}

To further explore high-order gene-environment interactions that were individually involved in cervical cancer 
risk, we performed the MDR analysis, as described previously $[17,18]$. This approach was used to find the main factor and the combination of multiple factors (in this case, SNPs and environmental risk factors) that were significantly associated with cancer risk. As a result, the model that minimized the prediction error and maximized the cross-validation consistency $(\mathrm{CVC})$ was chosen. To reduce the probability of bias, we used different random seeds to repeat the complete analysis for 10 times, and permutated the status of cases and controls in the data set then repeated the test 1000 times under the null hypothesis of no association. This analysis was performed by using the MDR V2.0 beta 8.2 program (http://www.multifactordimensionalityreduction.org/).

\section{Statistical analysis}

The differences in selected variables between cervical carcinoma cases and female controls were evaluated by the Pearson's $x^{2}$-test. The associations of genotypes with the risk of cervical carcinoma were estimated by computing odds ratios (ORs) and their 95\% confidence intervals (CIs) from both univariate and multivariate logistic regression models, with or without adjustment for age, age at primiparity, menopausal status and body mass index (BMI) [19]. The associations of SNP genotypes with cervical carcinoma risk were also stratified by demographic and clinico-pathologic variables. We also performed homogeneity test and logistic regression analysis to estimate and compare the risks between the strata and interactions between two factors, respectively. For all significant genetic effects observed in our study, we calculated the false-positive report probability (FPRP) with prior probabilities of $0.0001,0.001,0.01,0.1$ and 0.25 to test for false-positive associations [20]. A FPRP value $<0.2$ was considered a noteworthy and indicated a remained robust association for a given prior probability. Statistical power was estimated to detect an OR of 1.50/ 0.67 (for a risk/protective effect), with an $\alpha$ level equal to the observed $P$ value [20]. All statistical analyses were performed with SAS software (version 9.1; SAS Institute, Cary, NC), unless stated otherwise. All $P$ values were two-sided with a significance level of $P<0.05$.

\section{Results}

Among all studied subjects, 19 cases and three controls failed to be genotyped after repeated assays. Thus, the final analysis included 1,565 cases and 1,391 controls. As showed in Additional file 1: Table S1, there were no significant differences in the distributions of age between the cases and the controls with similar mean ages of $45.8( \pm 9.8)$ and $46.1( \pm 8.9)$ years, respectively $(P=0.226)$. The cases were more likely to be premenopausal $(72.5 \%$ vs. $60.5 \%)$, thinner (BMI $<25 \mathrm{~kg} / \mathrm{m}^{2}$, $78.2 \%$ vs. $65.9 \%)$ and younger at primiparity $(\leq 24 \mathrm{yr}$,
63.2\% vs. $51.0 \%$ ) than the controls. Because the differences in age at primiparity, menopausal status and BMI were significant between cases and controls (all $P<0.001)$, these variables were further adjusted for any residual confounding effect in later multivariate logistic regression analyses.

The genotype frequencies of the pri-miR-218 rs11134527 and $L A M B 3$ rs2566 SNPs as well as their associations with the risk of cervical carcinoma are summarized in Table 1 . All observed genotype distributions in the 1,391 controls agreed with the Hardy-Weinberg equilibrium (HWE, $P=0.083$ and 0.094 for rs11134527 and rs2566, respectively). In the recessive genetic model, the pri-miR-218 rs11134527 variant GG genotype was significantly associated with a decreased risk of cervical carcinoma compared with the $\mathrm{AA}$ and AA/AG genotypes (adjusted $\mathrm{OR}=0.79$ and 0.77 , 95\% $\mathrm{CI}=0.63-0.99$ and $0.63-0.95, P=0.039$ and 0.015 , respectively). However, this association was not observed for the $L A M B 3$ rs2566 SNP.

In stratification analyses, as showed in Table 2, under a recessive genetic model, a decreased cervical carcinoma risk associated with the pri-miR-218 rs11134527 GG genotype was more evident in women who were younger at primiparity ( $\leq 24 \mathrm{yr}$, adjusted $\mathrm{OR}=0.73,95 \%$ $\mathrm{CI}=0.56-0.96, \quad P=0.022$ ) or premenopausal (adjusted $\mathrm{OR}=0.73,95 \% \mathrm{CI}=0.57-0.94, P=0.013$ ), which was also observed for subgroups of SCC, FIGO stage I, stage II, positive pelvic LN, positive LVSI, deep cervical stromal invasion $(>1 / 2)$ and negative expression of ER and PR $(P=0.008,0.008,0.028,0.002,0.008,0.022,0.011$ and 0.014 , respectively). However, homogeneity tests suggested that there was no difference in risk estimates between the strata (Table 2), and no statistical evidence for interactions between the genotypes and these variables on the risk of cervical carcinoma (Additional file 1: Table S2).

We calculated the FPRP values for all the observed significant associations. When the assumption of prior probability was 0.1 , the association with the pri-miR-218 rs11134527 (GG vs. AA/AG) was still noteworthy in subgroups of premenopausal, SCC, FIGO stage I and positive pelvic LN (FPRP=0.189, 0.111, 0.163 and 0.153 , respectively) (Additional file 1: Table S3).

To further explore whether the pri-miR-218 rs11134527 variant could alter the local second structure of the pri-miR-218 mRNA, we performed the RNAfold online tool that is an online RNA secondary structure prediction software based on the minimum free energy (MFE) and found that the MFE changed from -182.5 $\mathrm{kcal} / \mathrm{mol}$ to $-126.0 \mathrm{kcal} / \mathrm{mol}$ when the nucleotide at the pri-miR-218 rs11134527 locus changed from A to $\mathrm{G}$ (Figure 1).

Moreover, using the MDR analysis and including these two SNPs and three risk factors, we found that age at 
Table 1 Logistic regression analysis of associations between genotypes of the LAMB3-miR-218 pathway and cervical cancer risk

\begin{tabular}{|c|c|c|c|c|c|c|c|}
\hline $\begin{array}{l}\text { Variants } \\
\text { Genotypes }\end{array}$ & $\begin{array}{l}\text { Cases } \\
(\mathrm{N}=1565)\end{array}$ & $\begin{array}{l}\text { Controls } \\
(\mathrm{N}=1391)\end{array}$ & $P^{*}$ & $\begin{array}{l}\text { Crude OR } \\
(95 \% \mathrm{Cl})\end{array}$ & $P$ & $\begin{array}{l}\text { Adjusted OR } \\
(95 \% \mathrm{Cl})\end{array}$ & $P^{* *}$ \\
\hline \multicolumn{8}{|c|}{ pri-miR-218 rs 11134527} \\
\hline AA & $588(37.6)$ & $512(36.8)$ & 0.085 & 1.00 & & 1.00 & \\
\hline AG & $752(48.1)$ & $638(45.9)$ & & $1.03(0.88-1.20)$ & 0.748 & $1.03(0.87-1.22)$ & 0.705 \\
\hline GG & $225(14.4)$ & $241(17.3)$ & & $0.81(0.65-1.01)$ & 0.061 & $0.79(0.63-0.99)$ & 0.039 \\
\hline AG/GG & $977(62.4)$ & $879(63.2)$ & $0.668^{\mathrm{a}}$ & $0.97(0.83-1.12)$ & 0.668 & $0.96(0.82-1.13)$ & 0.648 \\
\hline Additive model & & & & $0.93(0.84-1.03)$ & 0.148 & $0.92(0.82-1.02)$ & 0.111 \\
\hline Recessive model & & & $0.028^{b}$ & $0.80(0.66-0.98)$ & 0.028 & $0.77(0.63-0.95)$ & 0.015 \\
\hline \multicolumn{8}{|l|}{ LAMB3 rs2566 } \\
\hline CC & $667(42.6)$ & $570(41.0)$ & 0.431 & 1.00 & & 1.00 & \\
\hline$C T$ & $709(45.3)$ & $663(47.7)$ & & $0.91(0.78-1.07)$ & 0.252 & $0.89(0.76-1.05)$ & 0.165 \\
\hline$\pi$ & $189(12.1)$ & $158(11.4)$ & & $1.02(0.81-1.30)$ & 0.857 & $0.94(0.73-1.21)$ & 0.642 \\
\hline $\mathrm{CT} / \mathrm{TT}$ & $898(57.4)$ & $821(59.0)$ & $0.366^{\mathrm{a}}$ & $0.94(0.81-1.08)$ & 0.367 & $0.90(0.77-1.05)$ & 0.186 \\
\hline Additive model & & & & $0.98(0.88-1.09)$ & 0.707 & $0.94(0.84-1.06)$ & 0.325 \\
\hline Recessive model & & & $0.545^{b}$ & $1.07(0.86-1.34)$ & 0.546 & $1.00(0.79-1.27)$ & 1.000 \\
\hline
\end{tabular}

$\mathrm{OR}$, odds ratio; $\mathrm{Cl}$, confidence interval.

${ }^{*} X^{2}$ test for genotype distributions between cases and controls;

** Adjusted for age, age at primiparity, menopausal status, BMI in logistic regression models;

a for dominant genetic models;

b for recessive genetic models.

The results were in bold, if $P<0.05$.

primiparity was the best one-factor model with the highest CVC (100\%) and the lowest prediction error $(43.2 \%)$ among all five discrete factors. Intriguingly, the fivefactor model had a maximum CVC $(100 \%)$ and a minimum prediction error $(38.6 \%)$, which showed a better prediction than one factor (Table 3 ).

\section{Discussion}

In this relatively large hospital-based case-control study of 1,584 cervical cancer cases and 1,394 cancer-free female controls, we validated two previously reported significant miRNA-related SNPs involved in the LAMB3-miR-218 pathway for the risk of cervical carcinoma in Chinese populations [6]. We found that the pri-miR-218 rs11134527 variant GG genotype was significantly associated with a decreased risk of cervical carcinoma compared with the $\mathrm{AA}$ and $\mathrm{AA} / \mathrm{AG}$ genotypes, and our sample size had a statistical power of $94.9 \%$ to detect such an association. Further RNAfold prediction analysis showed a MFE changed from $-182.5 \mathrm{kcal} / \mathrm{mol}$ to $-126.0 \mathrm{kcal} / \mathrm{mol}$, when the nucleotide at the pri-miR-218 rs11134527 locus changed from A to G, indicating that this variant may act as a functional SNP, which affects the miRNA binding process and contributes to cervical cancer susceptibility. However, for the other SNP (i.e., $L A M B 3$ rs2566), our data did not have statistical evidence to support its association with cervical cancer risk. Our sample size had $100 \%$ statistical power to detect an OR of 1.57 that was reported by Zhou et al. [6]. The inconsistency for the LAMB3 rs2566 SNP between Zhou's study and ours may be caused by differences in selection of subjects, different catchments of the hospitals and residential regions as well as different sample sizes.

Recent studies have demonstrated that miRNAs may function as tumor suppressors and/or oncogenes in human cancers [21,22], because elevated or decreased expression of miRNAs has been found in various tumor types, which may alter the regulation of mRNA expression. It is of note that miRNAs regulate gene expression by the sequence-specific binding to the target mRNA, and these binding processes may be affected by SNPs located in the miRNA complementary site [23]. Therefore, it is important to understand the functional and evolutionary significance of related genetic variations in determining expression of miRNAs and mRNAs that interact with each other as well as with environmental risk factors in the related biological processes [23,24].

It is well known that genetic variants may modify cancer risk associated with environmental factors. Although there were no two-factor interactions between genotypes and environmental factors, using the MDR analysis [18], we further explored high-order multiple-factor interactions in associations with cervical cancer risk and found that age at primiparity was the strongest risk predictor among all the risk factors considered. Meanwhile, the interaction between the variant genotypes and other risk factors appeared 
Table 2 Stratification analysis for associations between genotypes of the LAMB3-miR-218 pathway and cervical cancer risk in the recessive genetic model

\begin{tabular}{|c|c|c|c|c|c|c|c|c|c|c|}
\hline \multirow[t]{2}{*}{ Variables } & \multicolumn{2}{|c|}{$\begin{array}{l}\text { rs11134527 } \\
\text { (cases/controls) }\end{array}$} & \multirow[t]{2}{*}{$\begin{array}{l}\text { Adjusted OR* } \\
(95 \% \mathrm{Cl})\end{array}$} & \multirow[t]{2}{*}{$P^{*}$} & \multirow[t]{2}{*}{$P^{* *}$} & \multicolumn{2}{|c|}{$\begin{array}{l}\text { rs2566 } \\
\text { (cases/controls) }\end{array}$} & \multirow[t]{2}{*}{$\begin{array}{l}\text { Adjusted OR* } \\
(95 \% \mathrm{CI})\end{array}$} & \multirow[t]{2}{*}{$P^{*}$} & \multirow[t]{2}{*}{$P^{* *}$} \\
\hline & AA/AG & GG & & & & $\mathrm{CC} / \mathrm{CT}$ & $T T$ & & & \\
\hline \multicolumn{11}{|l|}{ Age, years } \\
\hline$\leq 46$ (Mean) & $747 / 623$ & $136 / 131$ & $0.84(0.64-1.11)$ & 0.215 & 0.364 & $774 / 669$ & $109 / 85$ & $1.02(0.74-1.40)$ & 0.919 & 0.740 \\
\hline$>46$ (Mean) & $593 / 527$ & $89 / 110$ & $0.77(0.56-1.06)$ & 0.111 & & $602 / 564$ & $80 / 73$ & $1.00(0.69-1.45)$ & 0.995 & \\
\hline \multicolumn{11}{|c|}{ Age at primiparity, years } \\
\hline$\leq 24$ (Mean) & $797 / 568$ & $136 / 131$ & $0.73(0.56-0.96)$ & 0.022 & 0.452 & $822 / 625$ & $111 / 74$ & $1.12(0.82-1.54)$ & 0.482 & 0.460 \\
\hline$>24$ (Mean) & $468 / 566$ & $76 / 106$ & $0.86(0.62-1.20)$ & 0.386 & & $481 / 591$ & $63 / 81$ & $0.91(0.63-1.32)$ & 0.621 & \\
\hline \multicolumn{11}{|c|}{ Menopausal status } \\
\hline Premenopausal & $962 / 685$ & $164 / 155$ & $0.73(0.57-0.94)$ & 0.013 & 0.425 & $986 / 743$ & $140 / 97$ & $1.00(0.75-1.34)$ & 0.981 & 0.635 \\
\hline Postmenopausal & $366 / 463$ & $61 / 86$ & $0.90(0.62-1.32)$ & 0.600 & & $381 / 488$ & $46 / 61$ & $1.09(0.70-1.70)$ & 0.696 & \\
\hline \multicolumn{11}{|l|}{$\mathrm{BMI}, \mathrm{kg} / \mathrm{m}^{2}$} \\
\hline$<25$ & $1026 / 759$ & $175 / 157$ & $0.79(0.62-1.00)$ & 0.054 & 0.715 & $1061 / 810$ & $140 / 106$ & $1.00(0.75-1.32)$ & 0.973 & 0.739 \\
\hline$\geq 25$ & 288/390 & $47 / 84$ & $0.74(0.50-1.12)$ & 0.152 & & $295 / 422$ & $40 / 52$ & $1.02(0.64-1.63)$ & 0.939 & \\
\hline \multicolumn{11}{|l|}{ Histology } \\
\hline CINIII & $129 / 1150$ & $32 / 241$ & $1.06(0.68-1.66)$ & 0.789 & 0.169 & $137 / 1233$ & $24 / 158$ & $1.32(0.80-2.16)$ & 0.274 & 0.409 \\
\hline SCC & $1068 / 1150$ & $170 / 241$ & $0.74(0.59-0.92)$ & 0.008 & & $1096 / 1233$ & $142 / 158$ & $0.95(0.73-1.22)$ & 0.673 & \\
\hline Non-squamous & $138 / 1150$ & $23 / 241$ & $0.75(0.46-1.22)$ & 0.240 & & 138/1233 & 23/158 & $1.18(0.71-1.96)$ & 0.526 & \\
\hline \multicolumn{11}{|l|}{ FIGO stage } \\
\hline 1 & $633 / 1150$ & $97 / 241$ & $0.70(0.53-0.91)$ & 0.008 & 0.796 & $645 / 1233$ & $85 / 158$ & $0.94(0.70-1.27)$ & 0.689 & 0.341 \\
\hline$\|$ & $464 / 1150$ & $75 / 241$ & $0.72(0.54-0.97)$ & 0.028 & & $478 / 1233$ & $61 / 158$ & $0.96(0.69-1.35)$ & 0.830 & \\
\hline$|I| \sim \mid V$ & $43 / 1150$ & $5 / 241$ & $0.43(0.15-1.28)$ & 0.129 & & $39 / 1233$ & $9 / 158$ & $1.97(0.83-4.71)$ & 0.126 & \\
\hline \multicolumn{11}{|l|}{ Tumor size, cm } \\
\hline$<4$ & $801 / 1150$ & $139 / 241$ & $0.78(0.61-0.99)$ & 0.043 & 0.695 & $840 / 1233$ & $100 / 158$ & $0.88(0.66-1.16)$ & 0.365 & 0.100 \\
\hline$\geq 4$ & $428 / 1150$ & $69 / 241$ & $0.71(0.53-0.97)$ & 0.031 & & $426 / 1233$ & $71 / 158$ & $1.25(0.91-1.72)$ & 0.176 & \\
\hline \multicolumn{11}{|l|}{ Pelvic LN } \\
\hline Negative & $965 / 1150$ & $174 / 241$ & $0.83(0.66-1.04)$ & 0.098 & 0.095 & $1002 / 1233$ & $137 / 158$ & $1.00(0.77-1.29)$ & 0.970 & 0.819 \\
\hline Positive & $309 / 1150$ & $39 / 241$ & $0.55(0.37-0.80)$ & 0.002 & & $308 / 1233$ & $40 / 158$ & $0.96(0.64-1.42)$ & 0.828 & \\
\hline \multicolumn{11}{|l|}{ LVSI } \\
\hline Negative & $750 / 1150$ & $132 / 241$ & $0.80(0.63-1.02)$ & 0.073 & 0.305 & $783 / 1233$ & $99 / 158$ & $0.93(0.70-1.24)$ & 0.632 & 0.379 \\
\hline Positive & $390 / 1150$ & $56 / 241$ & $0.64(0.46-0.89)$ & 0.008 & & $387 / 1233$ & $59 / 158$ & $1.06(0.75-1.50)$ & 0.755 & \\
\hline \multicolumn{11}{|c|}{ Depth of cervical stromal invasion } \\
\hline$\leq 1 / 2$ & $584 / 1150$ & $99 / 241$ & $0.75(0.57-0.98)$ & 0.037 & 0.898 & $598 / 1233$ & $85 / 158$ & $1.08(0.81-1.45)$ & 0.602 & 0.709 \\
\hline$>1 / 2$ & $670 / 1150$ & $111 / 241$ & $0.74(0.57-0.96)$ & 0.022 & & $690 / 1233$ & $91 / 158$ & $0.94(0.70-1.26)$ & 0.660 & \\
\hline \multicolumn{11}{|l|}{ ER expression } \\
\hline Negative & $647 / 1150$ & $102 / 241$ & $0.71(0.55-0.92)$ & 0.011 & 0.146 & $671 / 1233$ & $78 / 158$ & $0.85(0.62-1.15)$ & 0.289 & 0.365 \\
\hline Positive & $50 / 1150$ & $13 / 241$ & $1.01(0.51-1.98)$ & 0.982 & & $54 / 1233$ & $9 / 158$ & $1.35(0.65-2.81)$ & 0.428 & \\
\hline \multicolumn{11}{|l|}{ PR expression } \\
\hline Negative & $677 / 1150$ & $110 / 241$ & $0.73(0.56-0.94)$ & 0.014 & 0.407 & $703 / 1233$ & $84 / 158$ & $0.87(0.65-1.18)$ & 0.370 & 0.836 \\
\hline Positive & $20 / 1150$ & $5 / 241$ & $0.94(0.32-2.80)$ & 0.911 & & $22 / 1233$ & $3 / 158$ & $1.13(0.33-3.84)$ & 0.851 & \\
\hline
\end{tabular}

OR, odds ratio; $\mathrm{Cl}$, confidence interval; BMI, body mass index; FIGO, International Federation of Gynecology and Obstetrics; CIN, cervical intraepithelial neoplasia; SCC, squamous cell carcinoma; LN, lymph node; LVSI, lympho-vascular space invasion; ER, estrogen receptor; PR, progesterone receptor.

* Logistic regression models with adjustment for age, age at primiparity, menopausal status and BMl;

** Homogeneity test.

The results were in bold, if $P<0.05$. 


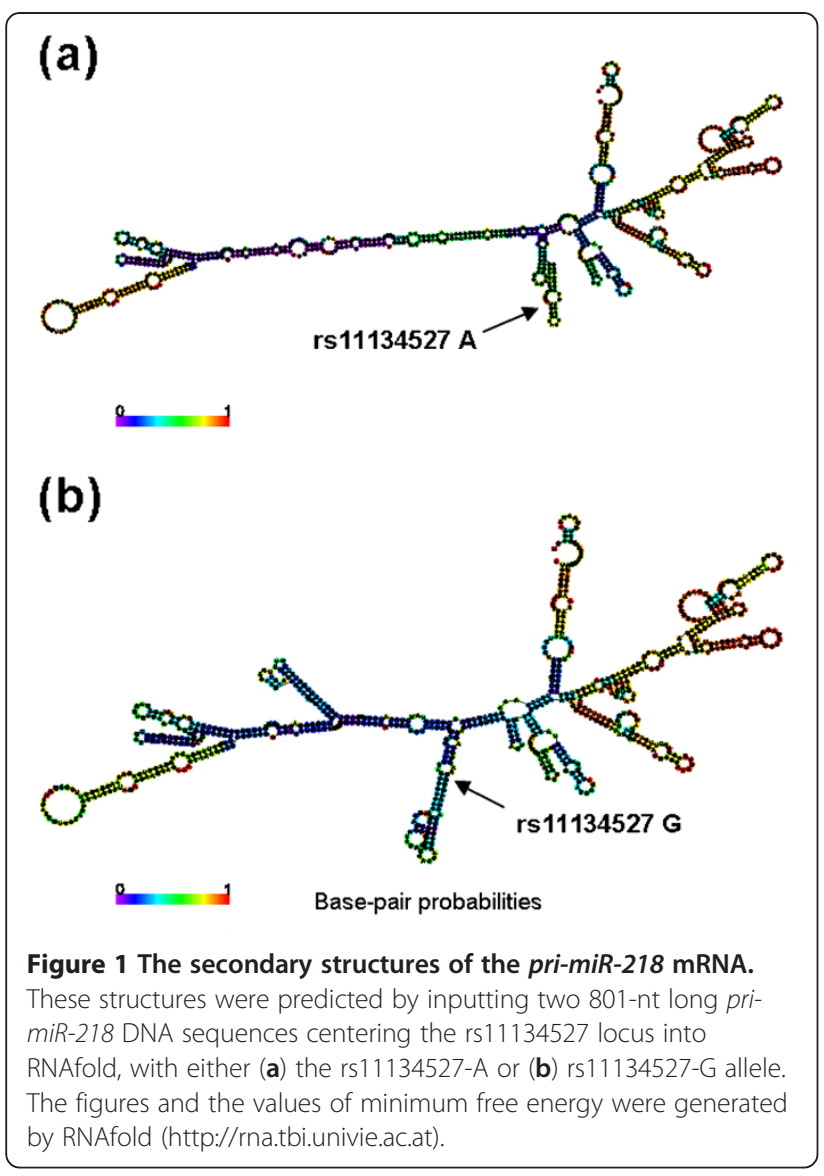

to modify the risk of cervical carcinoma, with the five-factor model being the best model.

MiR-218, is encoded by an intron of the SLIT2 tumor suppressor gene [25], is known to be associated with the development and progression of several cancers $[21,22]$. The decreased level of the miR-218 expression has been observed in cancers of the breast, ovary, lung and stomach $[22,26,27]$, and its low expression level was also correlated with tumor stage, LN metastasis and poor prognosis in gastric cancer [27]. Recently, Martinez et al. reported a decreased expression level of $m i R-218$ ( $>2$ fold) in HPV-16 or 18 positive cervical cancer cell lines (i.e., SiHa, CaSki and HeLa) as well as in cervical tumor tissues [12]. They also demonstrated $m i R-218$ as a specific cellular target of high-risk HPV types [12], suggesting that the down-regulation of $m i R-218$ is likely linked to the process of HPV-associated tumorgenesis. Based on the Microcosm Targets tool software (http://www.ebi. ac.uk/enright-srv/microcosm/), the mature $m i R$ - 218 was found to have an effect on the mRNA expression regulation through more than 900 target genes, including LAMB3 [12], RICTOR [28], ROBO1 [27] and BIRC5 [29], that may play important roles in cervical carcinogenesis. These genes were reported to participate in a number of cancer signaling pathways, such as the Wnt/ $\beta$-catenin, ERK/MAPK and Notch pathways [30]. Laminin-5 has been found as a sensitive marker of early invasion of cervical lesions [31]. LAMB3 that expressed in many epithelial tissues could induce carcinogenesis by increasing carcinoma cell migration and disturbing tumor microenvironment [13]. Moreover, LAMB3 increased expression levels of the HPV16 E6 oncoprotein in cervical cancer cells and this process might be mediated by miR218 [12], which indicates a possible mechanism of the LAMB3-miR-218 pathway involved in the development of cervical carcinoma.

It is known that the mRNA secondary structure is critical for mRNA-miRNA interactions and gene functions [32]. To investigate whether the pri-miR-218 rs11134527 SNP could alter the local second structure of the pri$m i R-218$ mRNA, we performed the RNAfold prediction analysis and found an obviously changed mRNA structure from rs11134527 allele A to G. These findings further suggest that germline genetic variations of pri$m i R-218$, such as rs11134527, may lead to an alteration of miR-218 expression and affect the miRNA binding process and thus are associated with cervical cancer susceptibility.

Several limitations of our study need to be addressed. Firstly, this hospital-based case-control study may have selection bias and information bias, which may be minimized by frequency-matching cases and controls as well as the adjustment for potential confounding factors in the final analyses. Secondly, only two miR-218-related SNPs involved in the LAMB3-miR-218 pathway (i.e., one

Table 3 MDR analysis for the cervical cancer risk prediction with and without LAMB3-miR-218 pathway genotypes

\begin{tabular}{lllll}
\hline $\begin{array}{l}\text { Number of risk } \\
\text { factors }\end{array}$ & Best interaction models by MDR analysis & $\begin{array}{l}\text { Cross- } \\
\text { validation }\end{array}$ & $\begin{array}{l}\text { Average prediction } \\
\text { error }\end{array}$ & $\begin{array}{l}\boldsymbol{P} \text { for permutation } \\
\text { test }\end{array}$ \\
\hline 1 & age at primiparity & $100 / 100$ & $43.2 \%$ & $<.0001$ \\
2 & age at primiparity, BMI & $100 / 100$ & $40.4 \%$ & $<.0001$ \\
3 & age at primiparity, menopausal status, BMI & $100 / 100$ & $39.2 \%$ & $<.0001$ \\
4 & age at primiparity, menopausal status, BMl, rs2566 & $83 / 100$ & $39.2 \%$ & $<.0001$ \\
$\mathbf{5}$ & $\begin{array}{l}\text { age at primiparity, menopausal status, BMI, } \\
\text { rs11134527, rs2566 }\end{array}$ & $\mathbf{1 0 0 / 1 0 0}$ & $\mathbf{3 8 . 6 \%}$ & $<.0001$ \\
\hline
\end{tabular}


in pri-miR-218 and the other in miR-218 binding site) were investigated in this study. Cancer is a complex and multifactorial disease, and any single SNP may not be sufficient for the prediction of the overall risk [33]. Future studies should include more genes and more SNPs, especially functional ones, associated with cervical cancer risk. Finally, we did not have enough information on other risk factors, especially HPV infection. This was because the hospital did not perform HPV and related subtype detection for the diagnosis of all cervical cancer cases, let alone for the female controls. A recent metaanalysis found that high-risk HPV16, 18 and 45 types accounted for a greater or equal proportion of HPV infections in cervical cancer, but not other high-risk HPV types, such as HPV33, 51 and 58 [34]. Therefore, HPV types could be confounders in estimating the risk associated with genetic factors.

\section{Conclusions}

In summary, in the current case-control study of 1,584 cases and 1,394 controls, we found that the pri-miR-218 rs11134527 SNP was associated with the risk of cervical carcinoma in Eastern Chinese women. Our findings suggest some possible interactions between genetic variations involved in the LAMB3-miR-218 pathway and other risk factors for cervical carcinoma. However, welldesigned prospective studies with larger sample sizes are required to validate our findings.

\section{Additional file}

Additional file 1: Table S1. Distributions of selected variables in cervical cancer cases and cancer-free female controls. Table S2. Interactions between genotypes of the LAMB3-miR-218 pathway and environmental factors on cervical cancer risk. Table S3. False-positive report probability values for associations between genotypes of the LAMB3-miR-218 pathway and cervical cancer risk.

\begin{abstract}
Abbreviations
miRNA: microRNA; nt: Nucleotide; UTR: Untranslated region; primiRNA: Primary miRNA; pre-miRNA: Precursor miRNA; SNP: Single nucleotide polymorphism; SCC: Squamous cell carcinoma; HPV: Human papillomavirus; LAMB3: Laminin 5 B3; FUSCC: Fudan University Shanghai Cancer Center; FIGO: International Federation of Gynecology and Obstetrics; LN: Lymph node; LVSI: Lympho-vascular space invasion; ER: Estrogen receptor; PR: Progesterone receptor; MAF: Minor allele frequency; MDR: Multifactor dimensionality reduction; CVC: Cross-validation consistency; OR: Odds ratio; Cl: Confidence interval; BMI: Body mass index; FPRP: False-positive report probability; HWE: Hardy-Weinberg equilibrium; MFE: Minimum free energy.
\end{abstract}

\section{Competing interests}

The authors declare that they have no competing interests.

\section{Authors' contributions}

Conception and design: QW, XW. In-person survey and data collection: XJC, XC, KDY, ZMS, MHS. Genotyping and Provision of study materials: TYS, MLZ, MYW, JH, XYZ. Data analysis and interpretation: TYS, QW. Manuscript writing: TYS, QW, XW. Final approval of manuscript: TYS, XJC, MLZ, MYW, JH, KDY, $Z M S, M H S, X Y Z, X C, X W, Q W$. All authors read and approved the final manuscript.

\section{Acknowledgements}

This study was supported by the funds from "China's Thousand Talents Program" Recruitment at Fudan University and by the Shanghai Committee of Science and Technology, China (Grant No.12DZ2260100). We would like to thank Yu-Hu Xin and Hong-Yu Gu from FUSCC for the technical support.

\section{Author details}

${ }^{1}$ Cancer Institute, Fudan University Shanghai Cancer Center, Shanghai, China. ${ }^{2}$ Department of Gynecologic Oncology, Fudan University Shanghai Cancer Center, Shanghai, China. ${ }^{3}$ Department of Breast Surgery, Fudan University Shanghai Cancer Center, Shanghai, China. ${ }^{4}$ Department of Pathology, Fudan University Shanghai Cancer Center, Shanghai, China. ${ }^{5}$ Department of Oncology, Shanghai Medical College, Fudan University, Shanghai, China.

${ }^{6}$ Department of Epidemiology, The University of Texas M.D, Anderson Cancer Center, Houston, Texas, USA.

Received: 15 August 2012 Accepted: 9 December 2012

Published: 15 January 2013

\section{References}

1. Lewis BP, Burge CB, Bartel DP: Conserved seed pairing, often flanked by adenosines, indicates that thousands of human genes are microRNA targets. Cell 2005, 120(1):15-20.

2. Zamore PD, Haley B: Ribo-gnome: the big world of small RNAs. Science 2005, 309(5740):1519-1524.

3. Bartel DP: MicroRNAs: genomics, biogenesis, mechanism, and function. Cell 2004, 116(2):281-297

4. Liu Z, Wei S, Ma H, Zhao M, Myers JN, Weber RS, Sturgis EM, Wei Q: A functional variant at the miR-184 binding site in TNFAIP2 and risk of squamous cell carcinoma of the head and neck. Carcinogenesis 2011, 32(11):1668-1674.

5. Chen AX, Yu KD, Fan L, Li JY, Yang C, Huang AJ, Shao ZM: Germline genetic variants disturbing the Let-7/LIN28 double-negative feedback loop alter breast cancer susceptibility. PLoS Genet 2011, 7(9):e1002259.

6. Zhou X, Chen X, Hu L, Han S, Qiang F, Wu Y, Pan L, Shen H, Li Y, Hu Z Polymorphisms involved in the miR-218-LAMB3 pathway and susceptibility of cervical cancer, a case-control study in Chinese women. Gynecol Oncol 2010, 117(2):287-290.

7. Jemal A, Bray F, Center MM, Ferlay J, Ward E, Forman D: Global cancer statistics. CA Cancer J Clin 2011, 61(2):69-90.

8. Tjalma WAA, Van Waes TR, Van den Eeden LEM, Bogers JJPM: Role of human papillomavirus in the carcinogenesis of squamous cell carcinoma and adenocarcinoma of the cervix. Best Practice; Res Clinical Obstetrics; Gynaecol 2005, 19(4):469-483.

9. Green J, Berrington De Gonzalez A, Sweetland S, Beral V, Chilvers C, Crossley B, Deacon J, Hermon C, Jha P, Mant D, et al: Risk factors for adenocarcinoma and squamous cell carcinoma of the cervix in women aged 20-44 years: the UK National Case-control Study of Cervical Cancer. Br J Cancer 2003, 89(11):2078-2086

10. Walboomers JM, Jacobs MV, Manos MM, Bosch FX, Kummer JA, Shah KV, Snijders PJ, Peto J, Meijer CJ, Munoz N: Human papillomavirus is a necessary cause of invasive cervical cancer worldwide. J Pathol 1999, 189(1):12-19.

11. Li Y, Liu J, Yuan C, Cui B, Zou X, Qiao Y: High-risk human papillomavirus reduces the expression of microRNA-218 in women with cervical intraepithelial neoplasia. J Int Med Res 2011, 38(5):1730-1736.

12. Martinez I, Gardiner AS, Board KF, Monzon FA, Edwards RP, Khan SA: Human papillomavirus type 16 reduces the expression of microRNA-218 in cervical carcinoma cells. Oncogene 2008, 27(18):2575-2582.

13. Marinkovich MP: Tumour microenvironment: laminin 332 in squamouscell carcinoma. Nat Rev Cancer 2007, 7(5):370-380.

14. Reshmi G, Surya R, Jissa VT, Babu PS, Preethi NR, Santhi WS, Jayaprakash PG, Pillai MR: C-T variant in a miRNA target site of $B C L 2$ is associated with increased risk of human papilloma virus related cervical cancer-an in silico approach. Genomics 2011, 98(3):189-193.

15. WHO: World Health Organization. International histological classification of tumours. 2010. Available at http://whoint/classifications/icd/en/

16. He J, Qiu LX, Wang MY, Hua RX, Zhang RX, Yu HP, Wang YN, Sun MH, Zhou XY, Yang YJ, et al: Polymorphisms in the XPG gene and risk of gastric cancer in Chinese populations. Hum Genet 2012, 131(7):1235-1244. 
17. Shi TY, Zhu ML, He J, Wang MY, Li QX, Zhou XY, Sun MH, Shao ZM, Yu KD, Cheng $X$, et al: Polymorphisms of the Interleukin 6 gene contribute to cervical cancer susceptibility in Eastern Chinese women. Hum Genet 2012, doi:10.1007/s00439-012-1245-4.

18. Ritchie MD, Hahn LW, Roodi N, Bailey LR, Dupont WD, Parl FF, Moore JH: Multifactor-dimensionality reduction reveals high-order interactions among estrogen-metabolism genes in sporadic breast cancer. Am J Hum Genet 2001, 69(1):138-147.

19. WHO: World Health Organization. Global database on body mass index. 2009. Available at http://appswhoint/bmi/indexisp.

20. Wacholder S, Chanock S, Garcia-Closas M, El Ghormli L, Rothman N: Assessing the probability that a positive report is false: an approach for molecular epidemiology studies. J Natl Cancer Inst 2004, 96(6):434-442.

21. Calin GA, Croce CM: MicroRNA-cancer connection: the beginning of a new tale. Cancer Res 2006, 66(15):7390-7394.

22. Zhang L, Huang J, Yang N, Greshock J, Megraw MS, Giannakakis A, Liang S, Naylor TL, Barchetti A, Ward MR, et al: microRNAs exhibit high frequency genomic alterations in human cancer. Proc Natl Acad Sci USA 2006, 103(24):9136-9141.

23. Saunders MA, Liang H, Li WH: Human polymorphism at microRNAs and microRNA target sites. Proc Natl Acad Sci USA 2007, 104(9):3300-3305.

24. Cho WC: Recent progress in genetic variants associated with cancer and their implications in diagnostics development. Expert Rev Mol Diagn 2010, 10(6):699-703.

25. Griffiths-Jones S, Grocock RJ, Van Dongen S, Bateman A, Enright AJ: miRBase: microRNA sequences, targets and gene nomenclature. Nucleic Acids Res 2006, 34(Database issue):D140-144.

26. Yanaihara N, Caplen N, Bowman E, Seike M, Kumamoto K, Yi M, Stephens RM, Okamoto A, Yokota J, Tanaka T, et al: Unique microRNA molecular profiles in lung cancer diagnosis and prognosis. Cancer Cell 2006, 9(3):189-198.

27. Tie J, Pan Y, Zhao L, Wu K, Liu J, Sun S, Guo X, Wang B, Gang Y, Zhang $Y$, et al: MiR-218 inhibits invasion and metastasis of gastric cancer by targeting the Robo1 receptor. PLoS Genet 2010, 6(3): 1000879.

28. Uesugi A, Kozaki K, Tsuruta T, Furuta M, Morita K, Imoto I, Omura K, Inazawa J: The tumor suppressive microRNA miR-218 targets the mTOR component Rictor and inhibits AKT phosphorylation in oral cancer. Cancer Res 2011, 71(17):5765-5778.

29. Alajez NM, Lenarduzzi M, Ito E, Hui AB, Shi W, Bruce J, Yue S, Huang SH, Xu W Waldron J, et al: MiR-218 suppresses nasopharyngeal cancer progression through downregulation of survivin and the SLIT2-ROBO1 pathway. Cancer Res 2011, 71(6):2381-2391.

30. Davidson MR, Larsen JE, Yang IA, Hayward NK, Clarke BE, Duhig EE, Passmore LH, Bowman RV, Fong KM: MicroRNA-218 is deleted and downregulated in lung squamous cell carcinoma. PLoS One 2010, 5(9):e12560.

31. Skyldberg B, Salo S, Eriksson E, Aspenblad U, Moberger B, Tryggvason K, Auer G: Laminin-5 as a marker of invasiveness in cervical lesions. J Nat/ Cancer Inst 1999, 91(21):1882-1887.

32. Kertesz M, lovino N, Unnerstall U, Gaul U, Segal E: The role of site accessibility in microRNA target recognition. Nat Genet 2007, 39(10):1278-1284.

33. Galvan A, loannidis JP, Dragani TA: Beyond genome-wide association studies: genetic heterogeneity and individual predisposition to cancer. Trends Genet 2010, 26(3):132-141.

34. Guan P, Howell-Jones R, Li N, Bruni L, de Sanjose S, Franceschi S, Clifford GM: Human papillomavirus types in 115,789 HPV-positive women: a meta-analysis from cervical infection to cancer. Int $J$ Cancer 2012, 131(10):2349-2359.

doi:10.1186/1471-2407-13-19

Cite this article as: Shi et al:: A pri-miR-218 variant and risk of cervical carcinoma in Chinese women. BMC Cancer 2013 13:19.

\section{Submit your next manuscript to BioMed Central and take full advantage of:}

- Convenient online submission

- Thorough peer review

- No space constraints or color figure charges

- Immediate publication on acceptance

- Inclusion in PubMed, CAS, Scopus and Google Scholar

- Research which is freely available for redistribution

Submit your manuscript at www.biomedcentral.com/submit 